\title{
Synthesis, properties and enzymatic biodegradation behavior of fluorinated poly(E-caprolactone)s
}

\author{
G. Acik $^{*}$ \\ Department of Chemistry, Faculty of Sciences and Letters, Piri Reis University, Tuzla, TR-34940 Istanbul, Turkey
}

Received 16 July 2019; accepted in revised form 9 September 2019

\begin{abstract}
This study reports on the synthesis of new fluoro functionalized poly( $\varepsilon$-caprolactone)s (F-PCLs) via ring-opening polymerization (ROP) of $\varepsilon$-caprolactone ( $\varepsilon$-CL) for different time intervals ( 24 and $48 \mathrm{~h}$.) by using 2,2,3,3,4,4,5,5-octafluoro-1-pentanol (OFP) as an initiator. The structure and properties of F-PCLs are investigated by Fourier-transform infrared (FT-IR), proton and fluorine 19 nuclear magnetic resonance $\left({ }^{1} \mathrm{H}-\mathrm{NMR}\right.$ and $\left.{ }^{19} \mathrm{~F}-\mathrm{NMR}\right)$ spectroscopies, gel permeation chromatography (GPC), energy dispersive scanning electron microscopy (SEM-EDS), atomic force microscopy (AFM), water contact angle (WCA) measurements, thermogravimetric analysis (TGA), and differential scanning calorimetry (DSC). Enzymatic degradation experiments are also conducted to study the biodegradation behavior of terminal F-PCLs. Experimental observations obtained by ${ }^{1} \mathrm{H}-\mathrm{NMR},{ }^{19} \mathrm{~F}-\mathrm{NMR}$ and $\mathrm{GPC}$ indicate that higher reaction time leads to the formation of higher fluorinated repeating units in F-PCLs. This observation is confirmed by results of SEM-EDS, AFM, WCA, DSC and TGA analyses, respectively. Based on the biodegradability study of F-PCLs in degradation solutions in the presence and absence of porcine pancreatic lipase, it can observed that utilization of more extended time in the ROP reaction medium decreases the biodegradation of resulting polymer. With the obtained features, biodegradable F-PCLs might have potential applications, particularly in the fields of drug delivery and tissue engineering, requiring improved thermal but lower wettability properties.
\end{abstract}

Keywords: biodegradable polymers, polymer synthesis, ring-opening polymerization, thermal properties

\section{Introduction}

Simultaneously with technological development and needs, the use of polymeric materials increases as solid waste environmental pollution is expanding day by day [1]. The main reason for this sharp increase is the rapid development of agriculture, medicine, and food and packaging industries. In recent years, biodegradable materials offered in different areas have been an increasing research interest due to environmental concerns that are important to every living creature in the world [2-4]. Thus, it is crucial to increase the biodegradability of polymeric materials to make a significant contribution to environmental sustainability.

Poly(DL-lactide) (PDLLA), poly(L-lactide) (PLLA), polyglycolide (PGA), poly ( $\beta$-hydroxybutyrate) (PHB) and poly( $\varepsilon$-caprolactone) (PCL) are considered the most widely used thermoplastic aliphatic polyesters known. Comparing to any other polymers, they present many attractive attributes, including a high biodegradation rate in the environment and the human body, good mechanical strength, processability. These easily degradable polymers have been a suitable choice for numerous food packaging, controlled drug delivery, and tissue engineering applications for a long time [5]. Among them, PCL that is obtained from either ROP of $\varepsilon$-CL or polycondensation of 6-hydroxyhexanoic acid is one of the biodegradable and biocompatible aliphatic polyester, which is soluble in most solvents, depending on its both degree of crystallinity and molecular weight $[6,7]$. 
The synthesis of fluorinated polymers is a topic of great interest in the biomaterial industry due to their distinctive characteristics such as water and oil repellency, high thermal, weather and chemical stability, low dielectric constant, low coefficient of friction, flame retardancy, and low surface energy [8]. Basically, there are two ways in the literature for the synthesis of fluorinated polymers; either direct polymerization of fluorinated monomers or introducing fluorinated moieties into the polymer chain using well-known chemical reactions [9]. Due to those of afore-mentioned reasons, they have been widely utilized in diverse applications, including chemistry [10], textiles [11], automotive [12], energy [13], bacterial coatings [14], and biomedical [15] fields. Considering the high-end applications of PCL, the need for F-PCLs with improved thermal properties, hydrophobicity, and altered biodegradation properties should not be overlooked. In this context, up to now, various methods for the synthesis PCL possessing fluorine groups, and their properties have been reported in literature [16-20]. Hence, in this work, by taking advantage of the simplicity of ring-opening polymerization of $\varepsilon$-CL, one-pot synthesis of F-PCLs was successfully conducted for different time intervals, and both the formation and properties of the final products were confirmed by using well-known techniques. The main goal of this study was to develop novel fluorinated biodegradable PCLs from their monomers by using a new fluoro compound, different from those utilized in the literature, and to investigate the effect of polymerization time on their molecular weight and distribution, morphology, root mean square (rms) surface roughness, water contact angle, and thermal and biodegradation properties of achieved F-PCLs.

\section{Materials and methods}

\subsection{Materials}

$\varepsilon$-caprolactone ( $\varepsilon$-CL, 97\%) as a monomer distilled from calcium hydride before use, 2,2,3,3,4,4,5,5octafluoro-1-pentanol (OFP, $\geq 98 \%$ ) as an initiator, stannous octoate $\left(\mathrm{Sn}(\mathrm{Oct})_{2}, 92.5-100 \%\right)$ as a catalyst and methanol as a precipitating solvent $\mathrm{CH} 3 \mathrm{OH}$ for HPLC, $\geq 99.9 \%$,) were procured from Sigma-Aldrich (Steinheim, Germany) in order to performed the syntheses. Phosphate buffer saline (PBS, $0.01 \mathrm{M}, \mathrm{pH}=$ 7.4) and porcine pancreatic lipase (EC 3.1.1.3., Type II, esterase enzyme) were used as received from Sigma-Aldrich and utilized for biodegradation experiments. Glass plates having dimensions of $76 \times 26 \mathrm{~mm}$ utilized for dip-coating procedure of F-PCLs were purchased from ISOLAB (Istanbul, Turkey).

\subsection{Characterization and measurements}

Spectroscopic Fourier transform infrared (FT-IR) analyses of F-PCLs were performed on a PerkinElmer (Lambda 25, Waltham, USA) FT-IR Spectrum Two Spectrometer equipped with a diamond ATR device at room temperature with scanning range from 400 to $4000 \mathrm{~cm}^{-1}$, and 8 scans and speed of $0.2 \mathrm{~cm}^{-1} / \mathrm{s}$, to indicate their functional group frequencies. ${ }^{1} \mathrm{H}-\mathrm{NMR}$ and ${ }^{19} \mathrm{~F}-\mathrm{NMR}$ spectra were recorded on a Varian $500 \mathrm{MHz}$ spectrometer system in chloroform$d_{3}$ with tetramethylsilane (TMS) as an internal standard given in ppm units at room temperature. Number average molecular weights $\left(M_{\mathrm{n}}\right)$ and polydispersity indexes $(\nexists)$ of obtained F-PCLs were determined by gel permeation chromatography (GPC) by a Viscotek GPCmax composed of a refractive index (RI) detector (VE 3580, Viscotek) and a pump module (GPC max, Viscotek, Houston, TX) at $1 \mathrm{~mL} / \mathrm{min}$ flow rate. An Autosampler system and $50 \mu \mathrm{L}$ injection volume were used in the analyses. The calibration of the RI detector was measured using polystyrene standards, having narrow molecular weight distribution. Three GPC columns (T3000, LT4000L and LT5000L, $300 \times 7.8$ ) with a guard column (CLM3008, 10×4.6 mm) were used for the tetrahydrofuran eluent at a flow rate of $1.0 \mathrm{~mL} / \mathrm{min}$ and at $35^{\circ} \mathrm{C}$. Viscotek OmniSEC 4.7.0 software was used to analyze the data. The surface morphologies and chemical compositions of the F-PCLs were determined by using energy dispersive scanning electron spectroscopy (SEM-EDS, JEOL JSM-6335F, Tokyo, Japan). The SEM-EDS measurements of F-PCLs were performed after the coating with $\mathrm{Pt}$ (Platin) by a sputter coater (Polaron SC7620, East Sussex, United Kingdom). AFM measurements were carried out by a portable atomic force microscope (ezAFM Nanomagnetics Instruments, Turkey) on two different regions of $5 \times 5 \mu \mathrm{m}$ area and the results were averaged with the scan speed of $2 \mathrm{~Hz}$., operating in tapping mode. A KSV Attension Theta Optical Tensiometer (CAM200, Vastra Frolunda, Sweden) static water contact angle (WCA) measuring device was used in the experiments of F-PCLs under air atmosphere at room temperature. Thermogravimetric analysis (TGA) of F-PCLs on samples of approximately $2-5 \mathrm{mg}$ weight 
was carried out by a SeikoSII TG-DTA 6300 TG/DTA analyzer heated from 25 to $600^{\circ} \mathrm{C}$ with a heating rate of $10^{\circ} \mathrm{C} / \mathrm{min}$ under $\mathrm{N}_{2}$ atmosphere. The glass transition $\left(T_{\mathrm{g}}\right)$ and melting $\left(T_{\mathrm{m}}\right)$ temperatures of the samples sealed in aluminum pans were determined by a DSC analyzer (Mettler Toledo DSC) using heating rate of $10^{\circ} \mathrm{C} / \mathrm{min}$ in the temperature ranging from 25 to $100^{\circ} \mathrm{C}$ under $\mathrm{N}_{2}$ atmosphere. Firstly, the samples were subjected to a heating-cooling cycle at $20^{\circ} \mathrm{C} / \mathrm{min}$ between 100 and $25^{\circ} \mathrm{C}$ to erase their thermal history. Then the samples were cooled to $-70^{\circ} \mathrm{C}$ and were heated to $100^{\circ} \mathrm{C}$ at $10^{\circ} \mathrm{C} / \mathrm{min}$, respectively. The second run was used to determine the DSC profiles of the samples.

\subsection{General procedure for the synthesis of fluorinated poly(E-caprolactone)s (F-PCLs)}

In a typical procedure, $\varepsilon$-CL $(10 \mathrm{~mL}, 90 \mathrm{mmol})$, OFP (314 $\mu \mathrm{L}, 2 \mathrm{mmol}), \mathrm{Sn}(\mathrm{Oct})_{2}\left(7 \mu \mathrm{L}, 2.2 \cdot 10^{-2} \mathrm{mmol}\right)$ were mixed in previously flamed one-necked flask equipped with magnetic stirrer bar in bulk under $\mathrm{N}_{2}$ atmosphere at $110^{\circ} \mathrm{C}$ for $24 \mathrm{~h}$. At the end of the defined time, the resulting mixture was precipitated into 10-fold excess of cold methanol, collected after filtration, dried under reduced pressure for 1 day, respectively. The dried samples were washed with methanol to get rid of the unreacted precursors and dried again for 1 day. Yields were calculated gravimetrically and were found as 87 and 94\% for F-PCL $24 \mathrm{~h}$ and F-PCL $48 \mathrm{~h}$., respectively. ${ }^{1} \mathrm{H}-\mathrm{NMR}$ $\left(500 \mathrm{MHz}, \mathrm{CDCl}_{3}, \delta\right): 5.93-6.15(\mathrm{~s}, 1 \mathrm{H}), 4.57(\mathrm{~s}$, $2 \mathrm{H}), 4.04(\mathrm{~s}, 2 \mathrm{H}), 2.28(\mathrm{~s}, 2 \mathrm{H}), 1.63(\mathrm{~s}, 4 \mathrm{H}), 1.36(\mathrm{~s}$, $2 \mathrm{H}) ;{ }^{19} \mathrm{~F}-\mathrm{NMR}\left(500 \mathrm{MHz}, \mathrm{CDCl}_{3}, \delta\right):-119,74(2 \mathrm{~F}$, $\left.\mathrm{CHF}_{2}-\mathrm{CF}_{2}-\mathrm{CF}_{2}-\mathrm{CF}_{2}\right),-125,37\left(2 \mathrm{~F}, \mathrm{CHF}_{2}-\mathrm{CF}_{2}-\mathrm{CF}_{2}\right)$, $-130.02\left(2 \mathrm{~F}, \mathrm{CHF}_{2}-\mathrm{CF}_{2}\right),-137,28\left(2 \mathrm{~F}, \mathrm{CHF}_{2}\right)$.

\subsection{Film coating procedure}

The dip-coating procedure of obtained F-PCLs on glass plate substrates which are washed with chromic acid solution and distilled water was performed using a precise homemade mechanical coater. The substrates were immersed in the prepared $50 \mathrm{mg} / \mathrm{mL}$ of F-PCL solutions with a drawing rate of $80 \mathrm{~mm} / \mathrm{min}$ for $3 \mathrm{~min}$. After this time, substrates coated with sample solutions were kept into a desiccator for $48 \mathrm{~h}$ to evaporate the residual solvents.

\subsection{Contact angle measurement}

Static water contact angles between F-PCL substrates and $5 \mu \mathrm{l}$ drops of LC-MS grade deionized water were measured using the sessile drop technique by a conventional digital camera. To prove the reliability of the data, all water contact angle values and images of the water droplet on sample surfaces were obtained from four different locations on each of the three substrates and expressed as mean \pm SD.

\subsection{Biodegradation experiment}

Biodegradability experiments of F-PCLs were performed by conducting enzymatic degradation experiment in PBS both in the presence of $1 \mathrm{mg} / \mathrm{mL}$ porcine pancreatic lipase and absence of it. The reason for the use of lipase enzyme in enzymatic degradation experiments is that it is well known that it has a splitting effect on ester bonds in a material [21, 22]. In a representative procedure, carefully weighed specimens placed into vials pre-washed with PBS were incubated in $8 \mathrm{~mL}$ of degradation solution by shaking at $37^{\circ} \mathrm{C}$ in a water bath for 30 days. To preserve the activity of the enzyme, biodegradation medium was exchanged every two days. Two samples were taken from the degradation solution after every 5 for 30 days, rinsed with distilled water and dried under reduced pressure for 1 day at $40^{\circ} \mathrm{C}$ to constant weight. The percentage residual weight losses $(R W L[\%])$ of the samples were determined before and after the enzymatic degradation studies and the results were calculated according to Equation (1):

$R W L[\%]=100-\frac{W_{0}-W_{1}}{W_{0}} \cdot 100$

where $W_{0}$ and $W_{1}$ were the weights of dry samples before and after degradation days, respectively. Each result was obtained from two specimens, and the mean values were reported with \pm SD.

\section{Results and discussion}

Polymers having fluorine groups are an important class of materials that contain a combination of features required for many critical applications. They have been utilized in various sectors such as automotive, textile, aerospace, aircraft, etc. [9, 23-25]. Because they present the backbone possessing strong $\mathrm{C}-\mathrm{C}$ bonds and stable $\mathrm{C}-\mathrm{F}$ bonds, increasing attention 


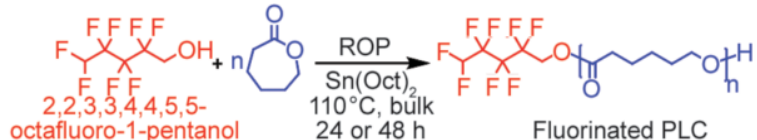

Figure 1. The representative synthesis route for the F-PCLs.

is devoted by researchers to obtain new fluorinated polymers with superior performance in recent years. From this perspective, in our study, the synthesis of fluorinated poly( $\varepsilon$-caprolactone)s by ROP of $\varepsilon$-CL monomer using - $\mathrm{OH}$ group of OFP which is fluorinating component was successfully performed in the presence of $\mathrm{Sn}(\mathrm{Oct})_{2}$ as a catalyst for different reaction times (Figure 1).

Firstly, FT-IR spectroscopic analysis was carried out to characterize the achieved F-PCL samples after the ring-opening polymerizations between $\varepsilon$-CL and OFP. The FT-IR spectra of P-PCLs were shown in Figure 2. In this figure, the peaks at 2935, 1725, and $1175 \mathrm{~cm}^{-1}$ have been associated with the $-\mathrm{CH}$ stretching, $>\mathrm{C}=\mathrm{O}$ stretching and etheric $\mathrm{C}-\mathrm{O}$ stretching vibrations, respectively. Meanwhile, in the zoomed image of this figure, one may notice that $-\mathrm{CF}_{2}$ stretching vibration peaks at 1145 and $1110 \mathrm{~cm}^{-1}$ [9]. These findings from FT-IR analysis indicate that the success of ring-opening polymerizations by using OFP. The structures of F-PCLs were further confirmed by ${ }^{1} \mathrm{H}$ and ${ }^{19} \mathrm{~F}$-NMR spectra, as indicated in Figure 3 , respectively. In the ${ }^{1} \mathrm{H}-\mathrm{NMR}$ spectra of F-PCLs, the characteristic methylene protons of $-\mathrm{CH}_{2}-\mathrm{CH}_{2}-\mathrm{CH}_{2}-\mathrm{O}-$, $(\mathrm{C}=\mathrm{O})-\mathrm{CH}_{2}-\mathrm{CH}_{2}$, $-\mathrm{CH}_{2}-\mathrm{CH}_{2}-\mathrm{O}-$ and $(\mathrm{C}=\mathrm{O})-\mathrm{CH}_{2}$ groups detected at
$1.36 \mathrm{ppm}(\mathbf{e}), \quad 1.63 \mathrm{ppm}(\mathbf{d}+\mathbf{f}), 2.28 \mathrm{ppm}(\mathbf{c})$ and $4.04 \mathrm{ppm}(\mathrm{g})$ were corresponded to the PCL repeating unit in F-PCLs. Furthermore, methylene protons of $\mathrm{CH}_{2}-\mathrm{C}=\mathrm{O}$ group and methine proton of $\mathrm{CH}-\mathrm{F}_{2}$ group appeared at $4.57 \mathrm{ppm}(\mathbf{b})$, and $5.93-$ $6.15 \mathrm{ppm}$ (a) were attributed to OFP moieties [9, 21]. On the other hand, as can be seen in ${ }^{19} \mathrm{~F}-\mathrm{NMR}$ spectra of F-PCLs, the peaks of $\mathrm{CHF}_{2}, \mathrm{CHF}_{2}-\mathrm{CF}_{2}$, $\mathrm{CHF}_{2}-\mathrm{CF}_{2}-\mathrm{CF}_{2}, \quad \mathrm{CHF}_{2}-\mathrm{CF}_{2}-\mathrm{CF}_{2}-\mathrm{CF}_{2}$ groups seemed at $-137,28 \mathrm{ppm}(\mathbf{w}),-130.02 \mathrm{ppm}(\mathbf{x})$, $-125,37 \mathrm{ppm}(\mathbf{y})$ and $-119,74 \mathrm{ppm}(\mathbf{z})$, respectively, coming from OFP moieties supported the formation of targeted fluorinated polymers [26]. Also, molecular weights of F-PCLs were firstly estimated ${ }^{1} \mathrm{H}-\mathrm{NMR}$ analysis using the areas of the all signed peaks on the spectra and found to be as 8500 and $12800 \mathrm{~g} \cdot \mathrm{mol}^{-1}$ for F-PCL $24 \mathrm{~h}$ and F-PCL $48 \mathrm{~h}$, respectively, assuming that all polymer chains have the same length and possess a fluorinated end group through Equation (2):

$M_{\mathrm{n}, \mathrm{NMR}}=\frac{\frac{\mathrm{c}+\mathrm{d}+\mathrm{e}+\mathrm{f}+\mathrm{g}}{2}}{\mathrm{a}+\frac{\mathrm{b}}{2}}$

In addition to the ${ }^{1} \mathrm{H}-\mathrm{NMR}$ analysis, molecular weights were also determined by GPC analysis. As can be seen in Figure 4, the synthesized F-PCLs obtained after ROPs indicated unimodal GPC curve without a shoulder. $Ð$ was 1.6 for F-PCL $24 \mathrm{~h}$, whereas it was 1.7 for F-PCL $24 \mathrm{~h}$. Compared with the F-PCL $24 \mathrm{~h}$ sample, the curve of F-PCL $48 \mathrm{~h}$ sample

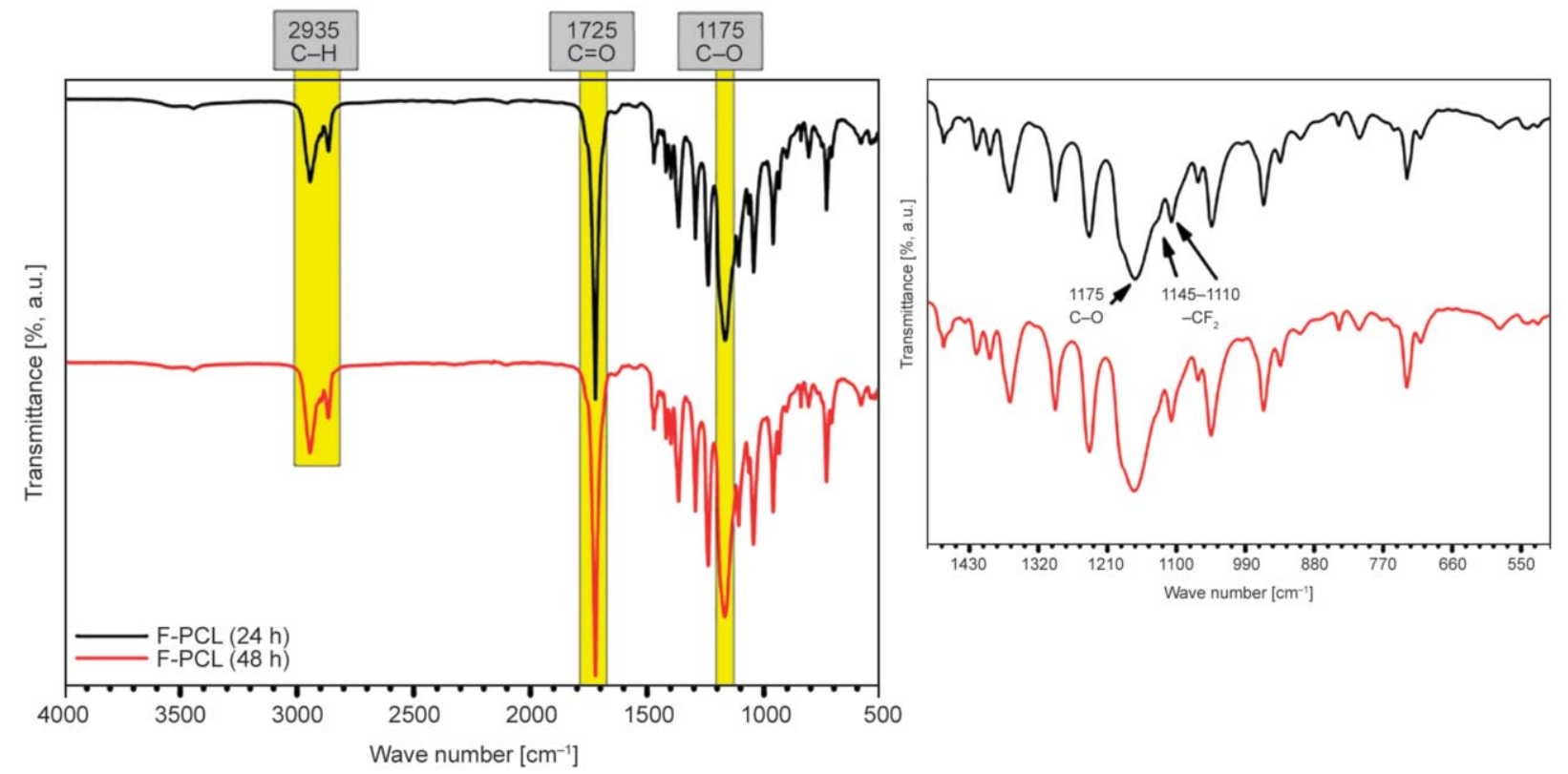

Figure 2. The FT-IR spectra of F-PCLs and its zoomed images. 


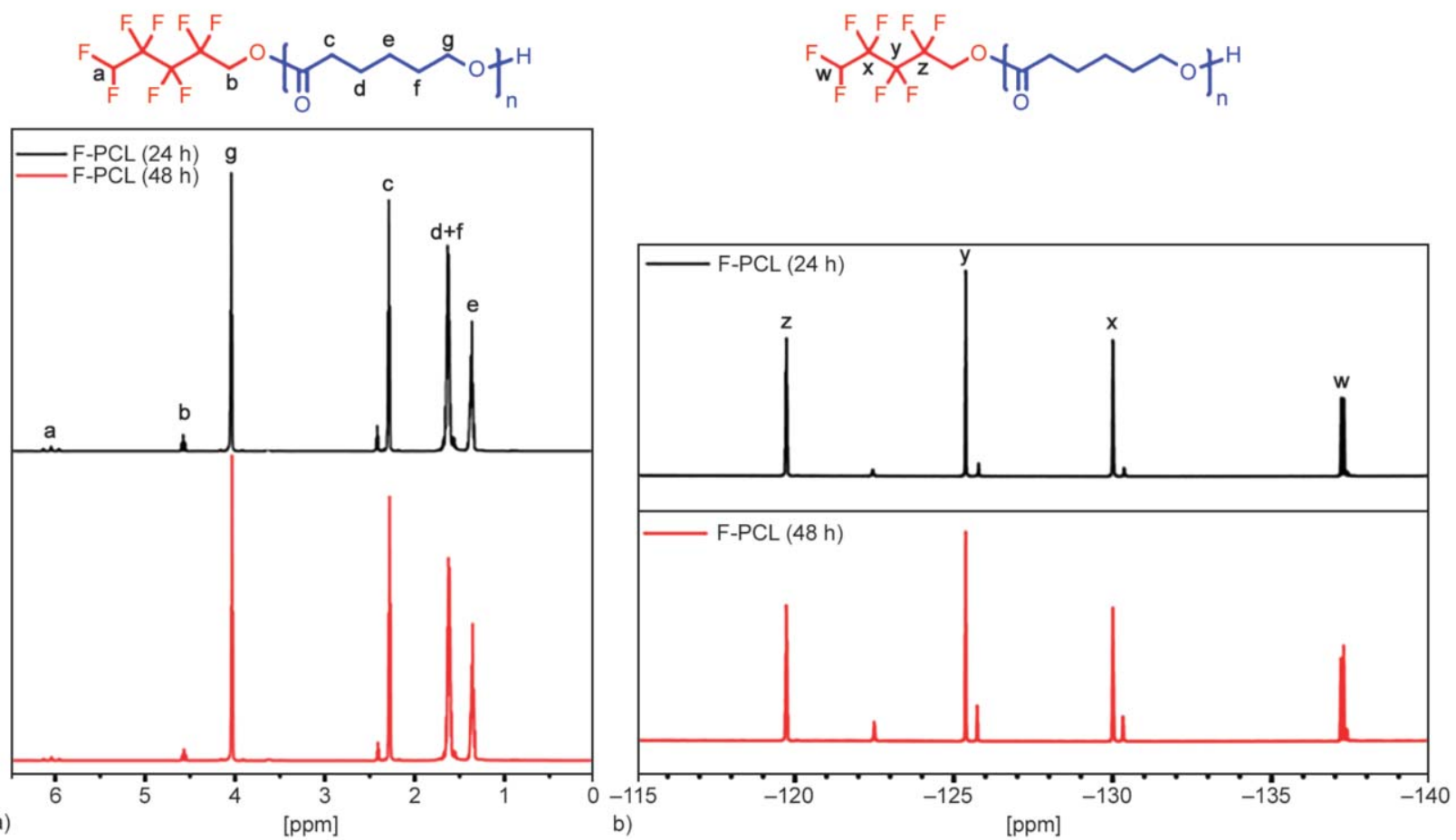

Figure 3. a) ${ }^{1} \mathrm{H}-\mathrm{NMR}$ and b) ${ }^{19} \mathrm{~F}-\mathrm{NMR}$ spectra of F-PCLs.

shifted to the higher molecular weight position due to the higher polymerization time. According to GPC analysis, the molecular weights were similar to the results determined from ${ }^{1} \mathrm{H}-\mathrm{NMR}$ analysis and were 9200 and $14000 \mathrm{~g} \cdot \mathrm{mol}^{-1}$ for F-PCL $24 \mathrm{~h}$ and F-PCL $48 \mathrm{~h}$, respectively.

SEM-EDS and AFM tests were conducted to determine the effect of polymerization reaction time on the surface fluorine contents, morphologies and rms surface roughness values of F-PCLs, and results were summarized in Table 1. The fluorine atomic percentage of F-PCL $24 \mathrm{~h}$ and F-PCL $48 \mathrm{~h}$ was found as 3.1 and $4.5 \%$, respectively from the SEM-EDS analysis (Figure 4). Figure 5 also compares the representative surface morphology of the F-PCLs prepared via ROP. Surface morphology of F-PCL $24 \mathrm{~h}$ sample is relatively smoother than that of the F-PCL $48 \mathrm{~h}$ surface as shown in SEM images. The AFM was utilized to

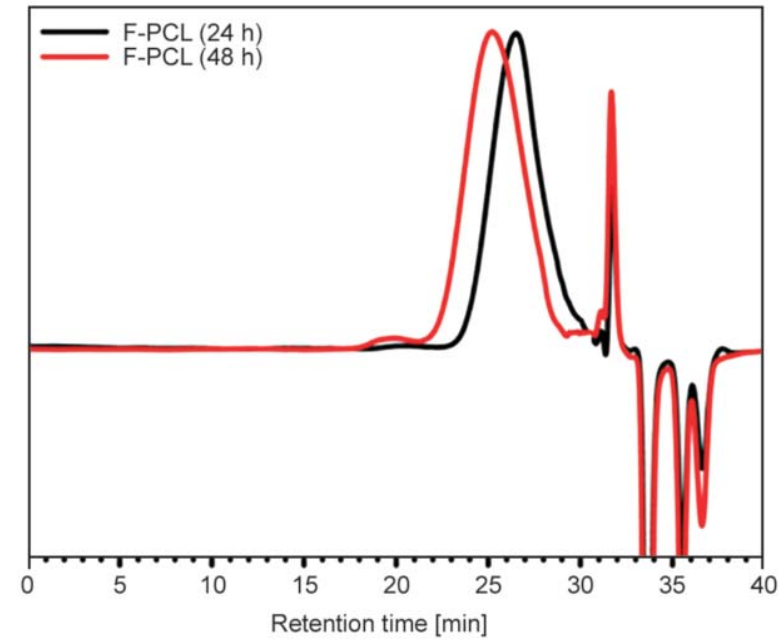

Figure 4. GPC chromatogram of F-PCLs.

understand better the surface morphologies and topographies of the samples. From the AFM results

Table 1. The data of the obtained fluorinated poly( $\varepsilon$-caprolactone)s.

\begin{tabular}{|c|c|c|c|c|c|c|c|c|c|c|}
\hline Sample & $\begin{array}{c}M_{\mathrm{n}, \mathrm{GPC}^{\mathrm{a}}} \\
{\left[\mathrm{g} \cdot \mathrm{mol}^{-1}\right]}\end{array}$ & $\boldsymbol{D}^{\mathbf{a}}$ & $\begin{array}{l}M_{\mathrm{n}, \mathrm{NMR}^{\mathrm{b}}} \\
{\left[\mathrm{g} \cdot \mathrm{mol}^{-1}\right]}\end{array}$ & $\begin{array}{c}F^{\mathbf{c}} \\
{[\%]}\end{array}$ & $\begin{array}{l}R m s^{\mathrm{d}} \\
{[\mathrm{nm}]}\end{array}$ & $\begin{array}{c}\mathbf{W C A}^{\mathrm{e}} \\
{\left[^{\circ}\right]}\end{array}$ & $\begin{array}{c}T_{\mathbf{i}}^{\mathbf{f}} \\
{\left[{ }^{\circ} \mathbf{C}\right]}\end{array}$ & $\begin{array}{c}T_{\max }{ }^{f} \\
{\left[{ }^{\circ} \mathrm{C}\right]}\end{array}$ & $\begin{array}{c}T_{\mathrm{g}}^{\mathrm{g}} \\
{\left[{ }^{\circ} \mathrm{C}\right]}\end{array}$ & $\begin{array}{c}T_{\mathrm{m}}{ }^{\mathrm{g}} \\
{\left[{ }^{\circ} \mathrm{C}\right]}\end{array}$ \\
\hline F-PCL $24 \mathrm{~h}$ & 9200 & 1.64 & 8500 & 3.1 & 36 & $70 \pm 1$ & 260 & 315 & -43 & 66 \\
\hline F-PCL $48 \mathrm{~h}$ & 14000 & 1.75 & 12800 & 4.5 & 49 & $78 \pm 1$ & 275 & 395 & -41 & 71 \\
\hline
\end{tabular}

${ }^{a}$ The number average molecular weights $\left(M_{\mathrm{n}, \mathrm{GPC}}\right)$ and polydispersity indexes $(Ð)$ determined by GPC analysis.

${ }^{\mathrm{b}}$ The number average molecular weights $\left(M_{\mathrm{n}, \mathrm{NMR}}\right)$ determined by ${ }^{1} \mathrm{H}-\mathrm{NMR}$ analysis using Equation (2).

'The fluorine atomic percentages determined by SEM-EDS analysis.

${ }^{\mathrm{d}}$ The root mean square surface roughnesses determined by AFM analysis.

${ }^{\mathrm{e}}$ The static water contact angles determined by WCA analysis.

${ }^{\mathrm{f}}$ The initial and maximum thermal degradation temperatures determined by TGA.

gThe glass transition and melting temperatures determined by DSC analysis. 

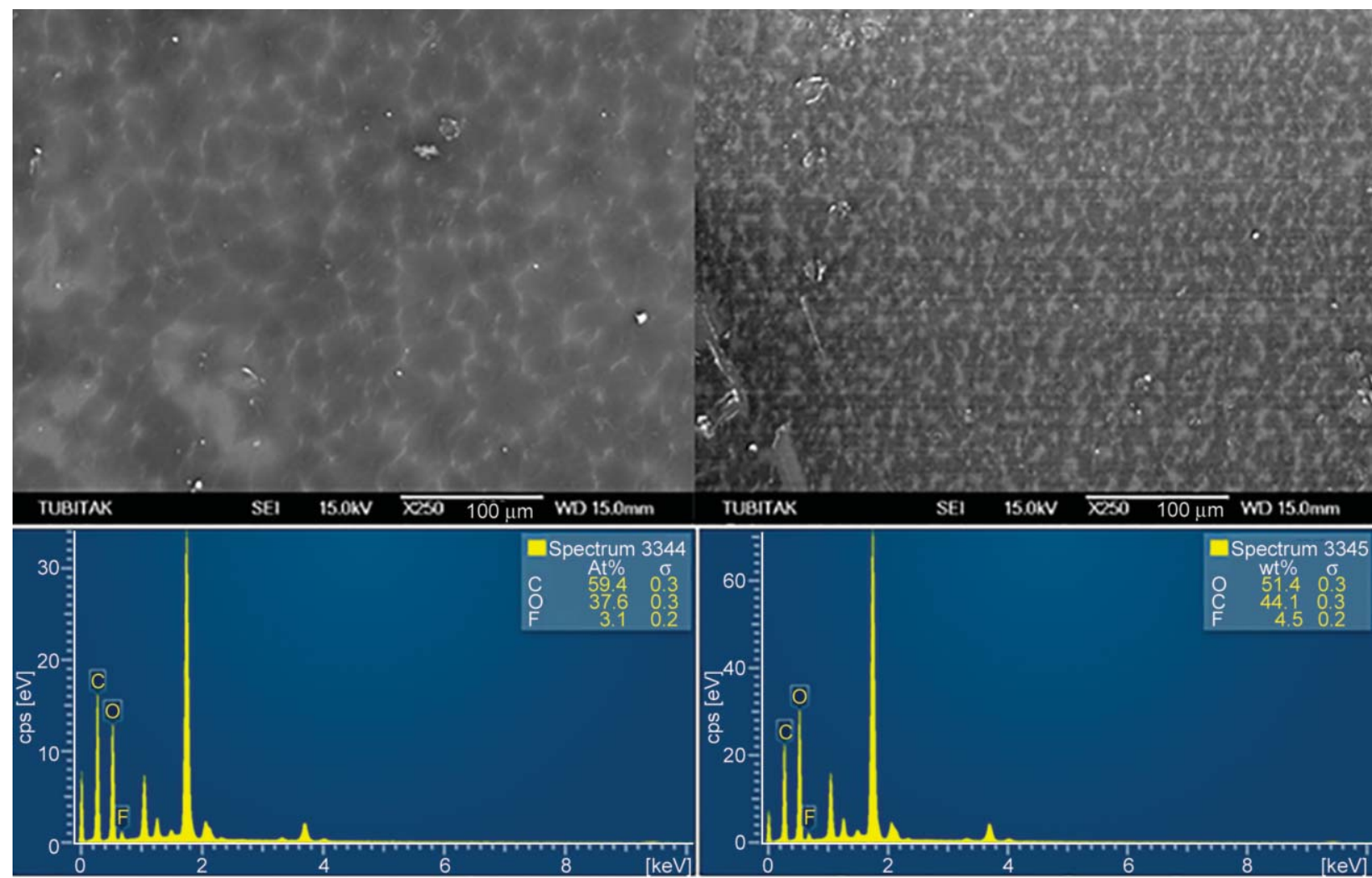

a)

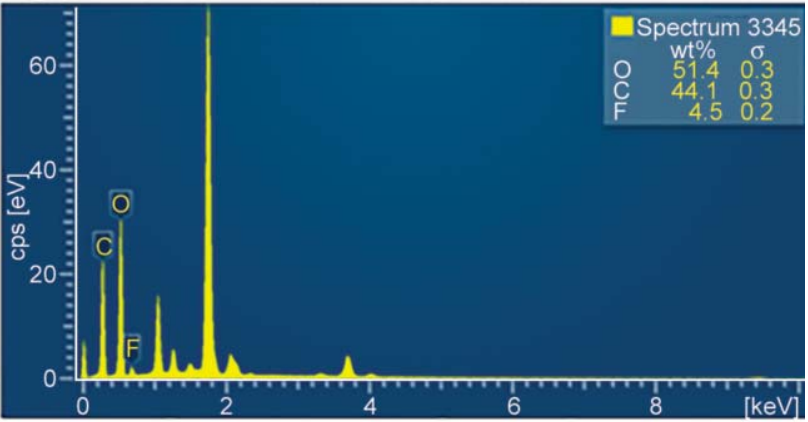

b)

Figure 5. The SEM-EDS photomicrographs and At $\%$ compositions of samples taken from the surface of the a) F-PCL 24 h, b) F-PCL $48 \mathrm{~h}$.

of F-PCL film samples deposited on glass plates, it can be concluded that the corresponding F-PCLs have rms surface roughness of was about 36 and $49 \mathrm{~nm}$, respectively (Table 1). It was concluded that results obtained from both SEM-EDS and AFM analyses were in concordance with each other [27]. These findings combined with the NMR and GPC analyses showed that F-PCL possessed higher fluorine content when implementing longer ring-opening polymerization duration.

Wettability of a surface which is generally evaluated by the contact angle is a characteristic feature of materials and largely depends on the surface morphology, surface energy, and the chemical composition [28]. The wettability properties of the substrates coated with the F-PCL samples were determined by static contact angle measurements. The photographs of coated sample surfaces and water drop images on them and WCA values of the samples were illustrated in Figure 6. The water contact angle value of virgin PCL is known in the hydrophobic character range depending on its chemical composition, structure, and morphology [29, 30]. However, in our recent work, we determined that WCA value of PCL prepared under similar reaction conditions and by

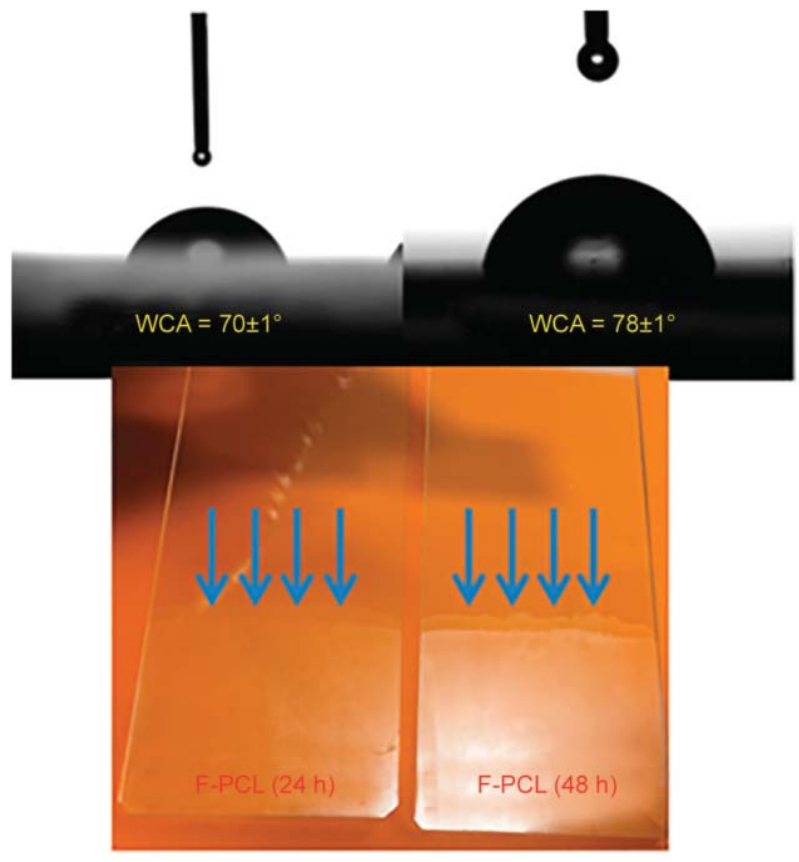

Figure 6. The static contact angle values of water drops on the F-PCL samples, their contact angle pictures, and F-PCL coated glass plate substrates.

film preparation procedure was $65 \pm 1.5^{\circ}$, indicating the hydrophilicity [21]. In the present study, WCA value of PCL was improved to $70 \pm 1$ and $78 \pm 1^{\circ}$, denoting the lower wettability, probably due to the 


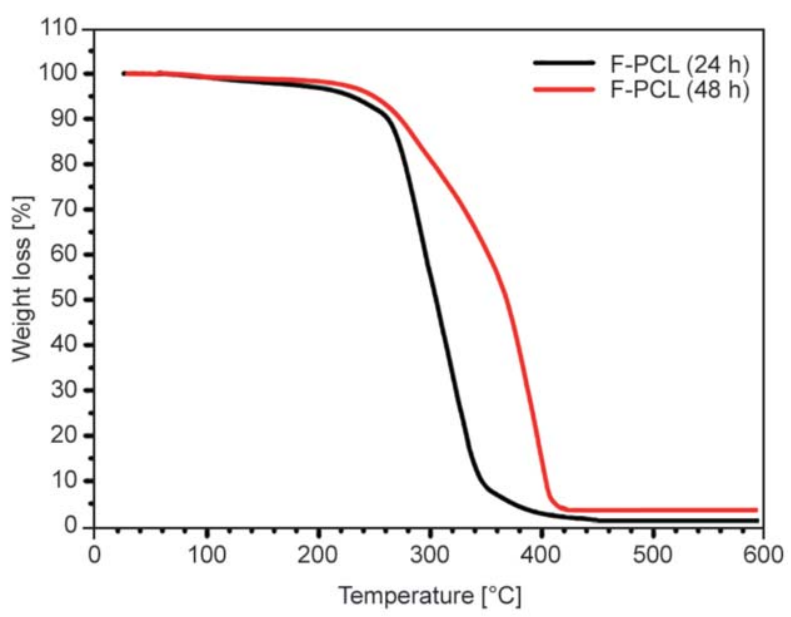

Figure 7. The overlaid TGA curves of F-PCLs as a function of temperature.

achieved increasing fluorinated segments on the polymer backbone, depending on the ring-opening polymerization time [31].

The thermal properties of the obtained F-PCLs were examined by TGA and DSC analyses. The overlaid profiles of them were as illustrated in Figures 7 and 8, and the data for all samples were summarized in Table 1. It is well-known in the literature that pristine PCL is decomposed in one step when it is subjected to heat [32]. In our case, this degradation behavior is approximately the same for its fluorinated derivatives (Figure 7). From the TGA mass loss curves for the F-PCL samples, it can be observed that first initial weight losses of about 1 to $3 \%$ between 90 and $120^{\circ} \mathrm{C}$ because of the removal moisture present in the specimens. As can be seen in Figure 7, the main thermal degradation step of F-PCL $24 \mathrm{~h}$ started at around $260^{\circ} \mathrm{C}$, while this step initiated at $275^{\circ} \mathrm{C}$ for F-PCL 48 h. Furthermore, the maximum weight loss temperature shifted to 395 from $315^{\circ} \mathrm{C}$. When the samples were compared among themselves, the main reason for these increases is that the high amount of $\mathrm{C}-\mathrm{F}$ bonds, which have a higher polarity than $\mathrm{C}-\mathrm{C}$ bonds in the polymer backbone cause higher attraction between the polymer chains [33].

Figure 8 indicated the comparative DSC thermograms of F-PCLs. In our previously published paper or other works in the literature, $T_{\mathrm{g}}$ value of neat PCL having semi-crystalline characteristic was around $-60^{\circ} \mathrm{C}$, while its $T_{\mathrm{m}}$ value was approximately $60^{\circ} \mathrm{C}$ $[16,34]$. In our present case, after (ROP) of $\varepsilon$-CL by using OFP, $T_{\mathrm{g}}$ value of F-PCL $24 \mathrm{~h}$ and F-PCL $48 \mathrm{~h}$ was found to be -43 and $-41^{\circ} \mathrm{C}$, respectively. On the other hand, $T_{\mathrm{m}}$ value was shifted to a higher temperature for F-PCL $24 \mathrm{~h}\left(66^{\circ} \mathrm{C}\right)$ and F-PCL $48 \mathrm{~h}\left(71^{\circ} \mathrm{C}\right)$.

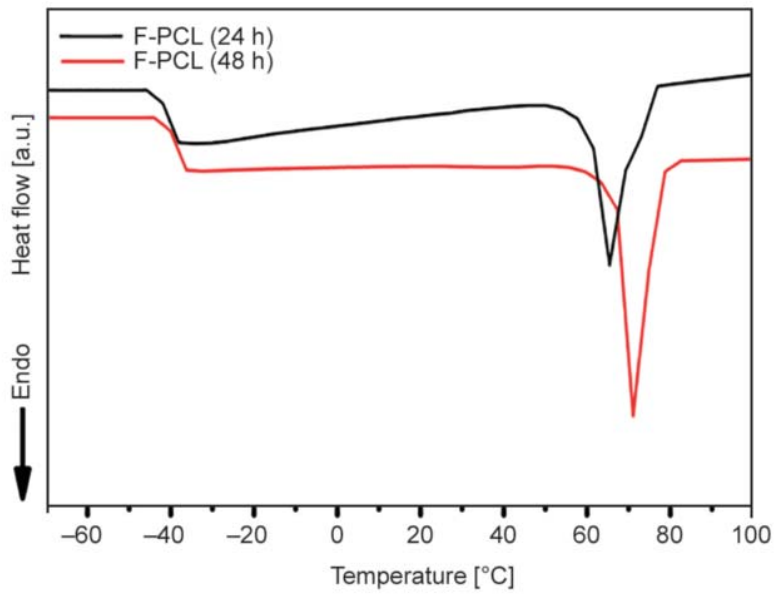

Figure 8. The comparative DSC thermograms of F-PCL samples given in arbitrary unit.

These increases could be probably because of either the higher amount of fluorine groups in the repeating unit of F-PCL $48 \mathrm{~h}$. or higher polarity of C-F groups than that of $\mathrm{C}-\mathrm{C}$ bonds leading to the restriction of molecular motion for polymer chains [35]. Finally, the higher thermal transition temperatures of F-PCLs compared to each other or pristine PCL were in good agreement with the TGA results.

Figure 9 below indicates the biodegradation profile of F-PCLs in PBS solutions both in the presence of lipase and absence of lipase as a function of time for 30 days. The two polymers obtained exhibited different degradation profiles during the experiments conducted. After the 30 days, the total residual weight for the F-PCL $24 \mathrm{~h}$ sample was $93.5 \%$, which was lower compared to that found for F-PCL $48 \mathrm{~h}(97 \%)$ in the absence of lipase. On the other hand, in the same period, the total residual weight for the F-PCL $24 \mathrm{~h}$ sample was $52 \%$, which was lower compared

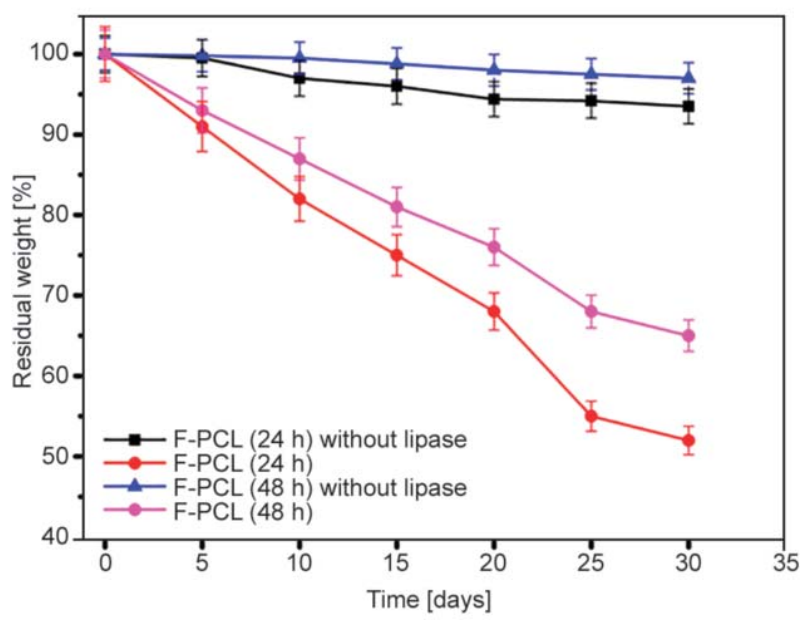

Figure 9. The percentage residual weights of F-PCLs as a function of degradation time in the presence or absence of porcine pancreatic lipase. 
to that found for F-PCL $48 \mathrm{~h}(65 \%)$ in the presence of lipase. The overall higher degradation rate of the F-PCL $24 \mathrm{~h}$ sample was attributed to the presence of hydrophobic polymer segments possessing higher fluorine groups, which impede lipase diffusion within the material [3].

\section{Conclusions}

In this work, two biodegradable fluorinated poly( $\varepsilon$ caprolactone)s which are a subgroup of polyester were successfully synthesized via ring-opening polymerization process of $\varepsilon$-caprolactone monomer by OFP used as an initiator. The effect of polymerization time interval on the molecular weight and distribution, morphology, root mean square surface roughness, wettability, thermal and biodegradation properties of achieved final F-PCLs was systematically examined. By the increasing of polymerization time, the spectral NMR analyses, and SEM-EDS, AFM and wettability measurements showed that polymer segments possessing fluorine groups were clearly increased, and thus rms surface roughness and WCA values of F-PCLs were enhanced. Furthermore, due to the higher polymerization time leading to higher fluorine content for obtained polymers, F-PCL $48 \mathrm{~h}$ exhibited higher thermal stability and transition temperatures in line with TGA and DSC analyses. During the biodegradation studies conducted both in the presence of porcine pancreatic lipase which is an esterase enzyme and absence of it, the F-PCL $48 \mathrm{~h}$ sample synthesized was more slowly degraded than F-PCL $24 \mathrm{~h}$ sample. Consequently, the obtained F-PCLs can be attractive material for particularly biomedical field, requiring biodegradable, higher thermal, but relatively lower wettability features.

\section{References}

[1] Leja K., Lewandowicz G.: Polymer biodegradation and biodegradable polymers-A review. Polish Journal of Environmental Studies, 19, 255-266 (2010).

http://www.pjoes.com/Polymer-Biodegradation-andBiodegradable-Polymers-a-Review,88379,0,2.html

[2] Mohanty A., Misra M. A., Hinrichsen G.: Biofibres, biodegradable polymers and biocomposites: An overview. Macromolecular materials and Engineering, 276, 1-24 (2000).

https://doi.org/10.1002/(SICI)1439-

2054(20000301)276:1<1::AID-MAME1>3.0.CO;2-W
[3] Acik G., Karabulut H. R. F., Altinkok C., Karatavuk A. O.: Synthesis and characterization of biodegradable polyurethanes made from cholic acid and L-lysine diisocyanate ethyl ester. Polymer Degradation and Stability, 165, 43-48 (2019).

https://doi.org/10.1016/j.polymdegradstab.2019.04.015

[4] Uysal N., Acik G., Tasdelen M. A.: Soybean oil based thermoset networks via photoinduced CuAAC click chemistry. Polymer International, 66, 999-1004 (2017). https://doi.org/10.1002/pi.5346

[5] Zhao H.: Enzymatic ring-opening polymerization (ROP) of polylactones: Roles of non-aqueous solvents. Journal of Chemical Technology and Biotechnology, 93, 9-19 (2018). https://doi.org/10.1002/jctb.5444

[6] Xu Q., Ren X., Chang Y., Wang J., Yu L., Dean K.: Generation of microcellular biodegradable polycaprolactone foams in supercritical carbon dioxide. Journal of Applied Polymer Science, 94, 593-598 (2004).

https://doi.org/10.1002/app.20726

[7] Labet M., Thielemans W.: Synthesis of polycaprolactone: A review. Chemical Society Reviews, 38, 3484 3504 (2009).

https://doi.org/10.1039/B820162P

[8] Kimura T., Kasuya M., Hatanaka K., Matsuoka K.: Synthesis of fluorinated polymers and evaluation of wettability. Molecules, 21, 358-364 (2016). https://doi.org/10.3390/molecules21030358

[9] Acik G., Cansoy C. E., Tasdelen M. A.: Synthesis of fluorinated polypropylene using CuAAC click chemistry. Journal of Applied Polymer Science, 136, 4707247081 (2019). https://doi.org/10.1002/app.47072

[10] Reisinger J. J., Hillmyer M. A.: Synthesis of fluorinated polymers by chemical modification. Progress in Polymer Science, 27, 971-1005 (2002). https://doi.org/10.1016/S0079-6700(02)00004-7

[11] Ramaratnam K., Tsyalkovsky V., Klep V., Luzinov I.: Ultrahydrophobic textile surface via decorating fibers with monolayer of reactive nanoparticles and non-fluorinated polymer. Chemical Communications, 2007, 4510-4512 (2007).

https://doi.org/10.1039/B709429A

[12] Drobny J. G.: Fluoropolymers in automotive applications. Polymers for Advanced Technologies, 18, 117 121 (2007). https://doi.org/10.1002/pat.807

[13] Zhang M., Guo X., Zhang S., Hou J.: Synergistic effect of fluorination on molecular energy level modulation in highly efficient photovoltaic polymers. Advanced Materials, 26, 1118-1123 (2014). https://doi.org/10.1002/adma.201304427

[14] Yang W. J., Neoh K-G., Kang E-T., Teo S. L-M., Rittschof D.: Polymer brush coatings for combating marine biofouling. Progress in Polymer Science, 39, 1017-1042 (2014)

https://doi.org/10.1016/j.progpolymsci.2014.02.002 
[15] Cardoso V., Correia D., Ribeiro C., Fernandes M., Lanceros-Méndez S.: Fluorinated polymers as smart materials for advanced biomedical applications. Polymers, 10, 161-187 (2018).

https://doi.org/10.3390/polym10020161

[16] Liu Q., Wang H., Chen L., Li W., Zong Y., Sun Y., Li Z.: Enzymatic degradation of fluorinated poly ( $\varepsilon$-caprolactone)(PCL) block copolymer films with improved hydrophobicity. Polymer Degradation and Stability, 165, 27-34 (2019).

https://doi.org/10.1016/j.polymdegradstab.2019.04.018

[17] Li W., Wang H., Li Z.: Preparation of golf ball-shaped microspheres with fluorinated polycaprolactone via single-solvent electrospraying for superhydrophobic coatings. Progress in Organic Coatings, 131, 276-284 (2019).

https://doi.org/10.1016/j.porgcoat.2019.02.039

[18] Wang H., Li W., Li Z.: Preparation of fluorinated PCL porous microspheres and a super-hydrophobic coating on fabrics via electrospraying. Nanoscale, 10, 1885718868 (2018). https://doi.org/10.1039/C8NR05793A

[19] Su S-K., Gu J-H., Lee H-T., Yu S-H., Wu C-L., Suen M-C.: Effects of an aromatic fluoro-diol and polycaprolactone on the properties of the resultant polyurethanes. Advances in Polymer Technology, 37, 1142-1152 (2018). https://doi.org/10.1002/adv.21773

[20] Wu C-L., Chiu S-H., Lee H-T., Suen M-C.: Synthesis and properties of biodegradable polycaprolactone/polyurethanes using fluoro chain extenders. Polymers for Advanced Technologies, 27, 665-676 (2016). https://doi.org/10.1002/pat.3737

[21] Acik G., Altinkok C., Tasdelen M. A.: Synthesis and characterization of polypropylene-graft-poly(L-lactide) copolymers by CuAAC click chemistry. Journal of Polymer Science Part A: Polymer Chemistry, 56, 25952601 (2018). https://doi.org/10.1002/pola.29241

[22] Acik G., Kamaci M., Altinkok C., Karabulut H. R. F., Tasdelen M. A.: Synthesis and properties of soybean oilbased biodegradable polyurethane films. Progress in Organic Coatings, 123, 261-266 (2018).

https://doi.org/10.1016/j.porgcoat.2018.07.020

[23] Gardiner J.: Fluoropolymers: Origin, production, and industrial and commercial applications. Australian Journal of Chemistry, 68, 13-22 (2015).

https://doi.org/10.1071/CH14165

[24] Améduri B., Boutevin B., Kostov G.: Fluoroelastomers: Synthesis, properties and applications. Progress in Polymer Science, 26, 105-187 (2001). https://doi.org/10.1016/S0079-6700(00)00044-7

[25] Lin J., Zheng C., Ye W., Wang H., Feng D., Li Q., Huan B.: A facile dip-coating approach to prepare $\mathrm{SiO}_{2}$ /fluoropolymer coating for superhydrophobic and superoleophobic fabrics with self-cleaning property. Journal of Applied Polymer Science, 132, 41458-41467 (2015). https://doi.org/10.1002/app.41458
[26] Houvenagel S., Picheth G., Dejean C., Brûlet A., Chennevière A., Couture O., Huang N., Moine L., Tsapis N.: End-chain fluorination of polyesters favors perfluorooctyl bromide encapsulation into echogenic PEGylated nanocapsules. Polymer Chemistry, 8, 2559-2570 (2017). https://doi.org/10.1039/C7PY00400A

[27] Uelzen T., Müller J.: Wettability enhancement by rough surfaces generated by thin film technology. Thin Solid Films, 434, 311-315 (2003). https://doi.org/10.1016/S0040-6090(03)00484-X

[28] Chau T. T., Bruckard W. J., Koh P. T. L., Nguyen A. V.: A review of factors that affect contact angle and implications for flotation practice. Advances in Colloid and Interface Science, 150, 106-115 (2009).

https://doi.org/10.1016/j.cis.2009.07.003

[29] Kasalkova N. S., Slepicka P., Kolska Z., Svorcik V.: Wettability and other surface properties of modified polymers. in 'Wetting and wettability' (ed.: Aliofkhazraei M.) IntechOpen, London, 323-355 (2015). https://doi.org/10.5772/60824

[30] Jiang W., Shi J., Li W., Sun K.: Morphology, wettability, and mechanical properties of polycaprolactone/hydroxyapatite composite scaffolds with interconnected pore structures fabricated by a mini-deposition system. Polymer Engineering and Science, 52, 2396-2402 (2012). https://doi.org/10.1002/pen.23193

[31] Li S., Huang J., Chen Z., Chen G., Lai Y.: A review on special wettability textiles: Theoretical models, fabrication technologies and multifunctional applications. Journal of Materials Chemistry A, 5, 31-55 (2017). https://doi.org/10.1039/C6TA07984A

[32] Lee J. M., Chae T., Sheikh F. A., Ju H. W., Moon B. M., Park H. J., Park Y. R., Park C. H.: Three dimensional poly( $\varepsilon$-caprolactone) and silk fibroin nanocomposite fibrous matrix for artificial dermis. Materials Science and Engineering: C, 68, 758-767 (2016). https://doi.org/10.1016/j.msec.2016.06.019

[33] Haloi D. J., Naskar K., Singha N. K.: Modification of chlorinated poly(propylene) via atom transfer radical graft copolymerization of 2-ethylhexyl acrylate: A brush-like graft copolymer. Macromolecular Chemistry and Physics, 212, 478-484 (2011). https://doi.org/10.1002/macp.201000506

[34] Acik G., Sey E., Tasdelen M.: Polypropylene-based graft copolymers via CuAAC click chemistry. Express Polymer Letters, 12, 418-428 (2018). https://doi.org/10.3144/expresspolymlett.2018.35

[35] Acik G., Altinkok C., Olmez H., Tasdelen M. A.: Antibacterial film from chlorinated polypropylene via CuAAC click chemistry. Progress in Organic Coatings, 125, 73-78 (2018). https://doi.org/10.1016/j.porgcoat.2018.08.029 